\title{
Erratum to: Selenium nanoparticles with low-level ionizing radiation exposure ameliorate nicotine-induced inflammatory impairment in rat kidney
}

Walid E. Zahran ${ }^{1}$ • Sawsan M. Elsonbaty ${ }^{2}$ - Fatma S. M. Moawed ${ }^{3}$

Published online: 17 August 2017

(C) Springer-Verlag GmbH Germany 2017

Erratum to: Environ Sci Pollut Res

https://doi.org/10.1007/s11356-017-9558-4

The original publication of this paper contains adjustment errors.

The adjusted images for figures 2 and 4 are now shown. In table 1, the accession no. for GAPDH was adjusted. The original article was corrected.

The online version of the original article can be found at doi:10.1007/ s11356-017-9558-4

Walid E. Zahran

walid_zahran@sci.asu.edu.eg

1 Biochemistry Department, Faculty of Science, Ain Shams University, Cairo, Egypt

2 Radiation Microbiology Department, National Center for Radiation Research and Technology, Atomic Energy Authority, Cairo, Egypt

3 Health Radiation Research Department, National Center for Radiation Research and Technology, Atomic Energy Authority, Cairo, Egypt 

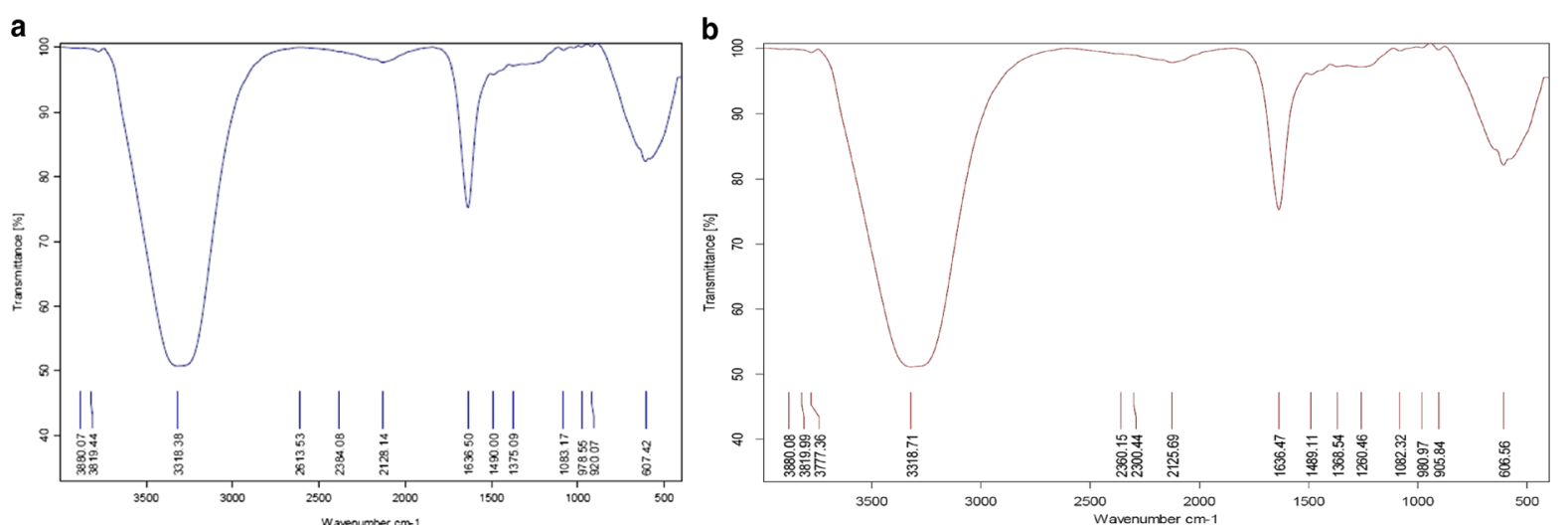

Fig. 2 Comparative FT-IR spectrums of ginger Zingiber officinale rhizome extract (a) and prepared ginger rhizome SeNPs (b) towards functional groups analysis

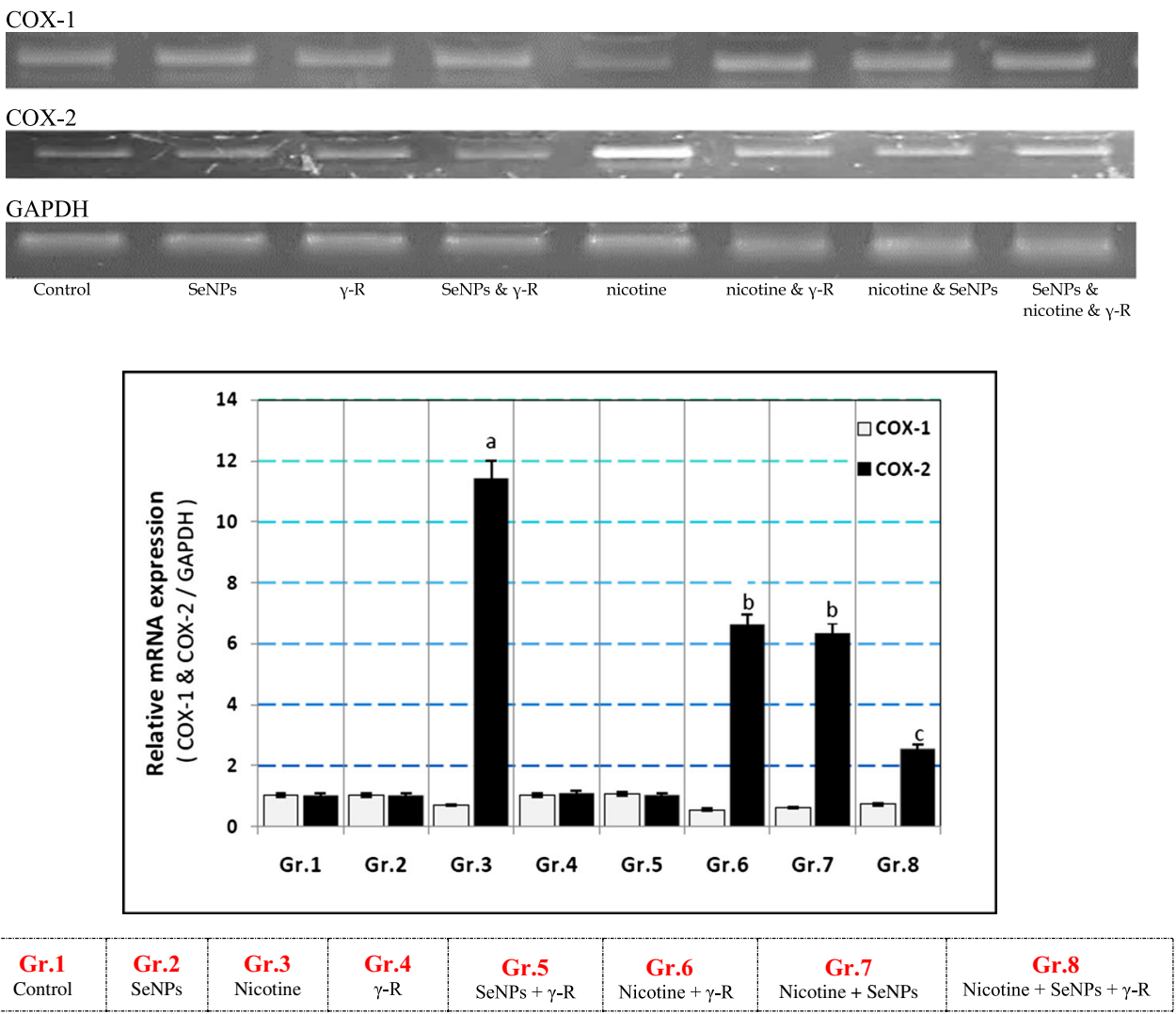

Fig. 4 Effect of nicotine upon COX-1 and COX-2 mRNA expression in treated rat groups. Data were expressed as relative quantification compared to control group using quantitative RT-PCR analysis. Each bar represents mean $\pm \mathrm{SD}(n=10)$. ${ }^{\mathrm{a}} P<0.05$ compared to control; ${ }^{\mathrm{b}} P<0.05$ compared to nicotine-treated group; ${ }^{\mathrm{c}} P<0.05$ compared to nicotine combined treatments 